OPEN ACCESS

Edited by:

Peter Hegyi,

University of Szeged, Hungary

Reviewed by:

Takahisa Murata,

The University of Tokyo, Japan

*Correspondence:

Yuki Hayashi

yuki.hayashi@sapmed.ac.jp

Specialty section:

This article was submitted to

Gastrointestinal Sciences,

a section of the journal

Frontiers in Physiology

Received: 29 December 2021

Accepted: 26 January 2022

Published: 11 February 2022

Citation:

Hayashi $Y$ and Nakase $H$ (2022) The Molecular Mechanisms of Intestinal Inflammation and Fibrosis in Crohn's

Disease.

Front. Physiol. 13:845078.

doi: 10.3389/fphys.2022.845078

\section{The Molecular Mechanisms of Intestinal Inflammation and Fibrosis in Crohn's Disease}

\author{
Yuki Hayashi* and Hiroshi Nakase \\ Department of Gastroenterology and Hepatology, Sapporo Medical University of Medicine, Sapporo, Japan
}

Crohn's disease $(\mathrm{CD})$ is an inflammatory bowel disease (IBD) with repeated remissions and relapses. As the disease progresses, fibrosis and narrowing of the intestine occur, leading to severe complications such as intestinal obstruction. Endoscopic balloon dilatation, surgical stricture plasty, and bowel resection have been performed to treat intestinal stenosis. The clinical issue is that some patients with CD have a recurrence of intestinal stenosis even after the medical treatments. On the other hand, there exist no established medical therapies to prevent stenosis. With the progressive intestinal inflammation, cytokines and growth factors, including transforming growth factor (TGF- $\beta$ ), stimulate intestinal myofibroblasts, contributing to fibrosis of the intestine, smooth muscle hypertrophy, and mesenteric fat hypertrophy. Therefore, chronically sustained inflammation has long been considered a cause of intestinal fibrosis and stenosis. Still, even after the advent of biologics and tighter control of inflammation, intestinal fibrosis's surgical rate has not necessarily decreased. It is essential to elucidate the mechanisms involved in intestinal fibrosis in CD from a molecular biological level to overcome clinical issues. Recently, much attention has been paid to several key molecules of intestinal fibrosis: peroxisome proliferator-activating receptor gamma (PPAR $\gamma$ ), toll-like receptor 4 (TLR4), adherent-invasive Escherichia coli (AIEC), Th17 immune response, and plasminogen activator inhibitor 1 (PAl-1). As a major problem in the treatment of $\mathrm{CD}$, the pathophysiology of patients with $C D$ is not the same and varies depending on each patient. It is necessary to integrate these key molecules for a better understanding of the mechanism of intestinal inflammation and fibrosis.

\section{Keywords: intestinal fibrosis, IBD, Crohn's disease, PPAR $\gamma$, TLR4, AIEC, Th17, PAI-1}

\section{INTRODUCTION}

Crohn's disease (CD) is a chronic inflammatory bowel disease (IBD) that progresses irreversibly, with more than $30 \%$ of the patients gradually developing intestinal fibrosis, which leads to complications, such as intestinal obstruction, perforation, and fistula (Rieder et al., 2013). The general mechanism of intestinal fibrosis is acute or chronic inflammation that leads 
to the destruction of the extracellular matrix (ECM) around the site of inflammation. Additionally, cytokines and growth factors, such as transforming growth factor (TGF- $\beta$ ), stimulate the ECM component cells, namely the intestinal myofibroblasts (Bettenworth and Rieder, 2017). This results in excessive ECM re-synthesis, which, in turn leads to intestinal fibrosis. In the case of $\mathrm{CD}$, chronic inflammation is the main factor leading to intestinal fibrosis. The currently implemented treatments for intestinal stricture are limited to mechanical treatments, such as endoscopic balloon dilation, surgical strictureplasty, and bowel resection (Crespi et al., 2020). However, some patients with $\mathrm{CD}$ have recurrent intestinal stenosis, even after the mechanical treatment (Scarpa et al., 2003). Minimally invasive treatment strategies, specifically drug administration, are desirable for CD patients at risk of developing intestinal stenosis. Therefore, it is important to understand the underlying molecular mechanisms of inflammation and fibrosis for developing such therapies. In this review, we have attempted to provide a comprehensive description of the molecular mechanisms underlying intestinal inflammation and fibrosis in the case of CD.

\section{PATHOLOGICAL CHARACTERISTICS OF CD AND INTESTINAL STENOSIS}

Crohn's disease is a chronic IBD that mainly occurs in the small and large intestines. Histologically, it is characterized by the fibrosis-induced thickening of the intestinal wall, mainly the submucosal layer, and an increase in smooth muscle cell growth (Van Assche et al., 2004). The increased mRNA and protein expression of cytokines, such as TGF- $\beta 1$ and insulinlike growth factor 1 (IGF-1), in all intestinal layers coincident with the inflammation sites and the increased deposition of ECM proteins synthesized by myofibroblasts induce intestinal fibrosis (Lawrance et al., 2001b; Fiocchi and Lund, 2011). Activated myofibroblasts are required to produce the ECM. These activated myofibroblasts include pre-existing myofibroblasts that are activated by inflammatory stimulants and de-differentiated mesenchymal cells [fibroblasts, smooth muscle cells, epithelial cells transformed by epithelial-mesenchymal transition (EMT), and endothelial cells transformed by endothelial-mesenchymal transition (EndoMT)]. There are patterns of differentiation of epithelial cells by EMT and endothelial cells by EndoMT, including stellate cells, pericytes, and bone marrow stem cells (Wynn, 2007). In the case of intestinal fibrosis caused by non-specific intestinal inflammation, once the inflammation subsides, the increased production of the fibrous matrix is suppressed, and the matrix metalloproteinase (MMP)-induced degradation of the fibrous matrix is promoted. Finally, intestinal fibrosis and the associated stenosis improve with a certain degree of plasticity (Rieder et al., 2007). However, in $\mathrm{CD}$, even after the inflammation subsides, fibrosis progresses due to abnormal production of the fibrous matrix or reduced degradation of the matrix by the MMPs, both of which result in abnormal deposition of ECM (Lawrance et al., 2001a; Speca et al., 2012). This probably accounts for the high number of endoscopic or surgical treatments of stenosis in recent years, even after immunosuppressive therapies, such as biologics, have extensively improved the intestinal inflammation in CD (Rieder et al., 2017). Another significant feature of CD is thickened mesenteric fat ("creeping fat"; Schäffler and Herfarth, 2005). "Fat wrapping" is defined as the condition in which more than $50 \%$ of the intestinal surface is covered with adipose tissue, and the intestinal surface on the side of the foregut is also covered with fat (Sheehan et al., 1992). Creeping fat is predominantly found in CD patients, and it is generally absent in patients with ulcerative colitis (UC). The physiological implications of creeping fat have not yet been studied. However, recent reports have demonstrated that this massive fat (Desreumaux et al., 1999; Weisberg et al., 2003; Karmiris et al., 2006; Acedo et al., 2011).

\section{PEROXISOME PROLIFERATOR- ACTIVATING RECEPTOR GAMMA}

Peroxisome proliferator-activated receptors (PPARs) are nuclear receptors that regulate the expression of genes involved in energy metabolism, cell development, and cell differentiation. There are three members of PPARs, namely PPAR $\alpha$, peroxisome proliferator-activating receptor gamma (PPAR $\gamma)$, and PPAR $\beta / \delta$. Upon ligand binding, the PPARs translocate into the nucleus, form a heterodimer with retinoid $\mathrm{X}$ receptors, and bind to peroxisome proliferator-responsive elements (PPREs) to regulate the transcription of target genes (Mangelsdorf et al., 1995; Zhang et al., 2007; Chan and Wells, 2009; Figure 1). There have been reports about several ligands (full agonists, partial agonists, and antagonists) targeting the PPARs, based on which medical research and drug discovery have been actively pursued (Kroker and Bruning, 2015; Mirza et al., 2019). Incidentally, 5-aminosalicylic acid (5-ASA), which is widely used in the treatment of IBD, is also a PPAR $\gamma$ ligand (Rousseaux et al., 2005; Iacucci et al., 2010). The expression of PPAR $\gamma$ in the intestinal epithelium is possibly related to the intestinal microbiota composition. In fact, butyrate production by the intestinal microbiota activates PPAR $\gamma$ signaling in the colonic epithelium, thereby resulting in the $\beta$-oxidation of energy substrates in colonic epithelial cells (colonocytes). This, in turn, reduces the activity of respiratory electron receptors for intestinal bacteria, which may be pathogenic (Byndloss et al., 2017). Additionally, toll-like receptor 4 (TLR4)-transfected colonocytes have been proven to prevent the abnormal growth of potentially pathogenic bacteria. In TLR4-transfected cancer coli-2 (Caco-2) cells, the TLR4 signaling pathway upregulates PPAR $\gamma$ expression as well as the expression of a PPAR $\gamma$ dependent reporter in an inhibitor of nuclear factor kappalight-chain-enhancer of activated B cells ( $\mathrm{\kappa} \kappa \beta)$-dependent manner. Similarly, PPAR $\gamma$ expression is decreased in the colon of mice devoid of functional TLR4 (Lpsd/Lpsd mice; YamamotoFurusho et al., 2014). Mucosal biopsies from patients with active UC reveal a decreased expression of PPAR $\gamma$ mRNA, which is negatively correlated with the endoscopic severity of the disease (Dubuquoy et al., 2003; Yamamoto-Furusho 


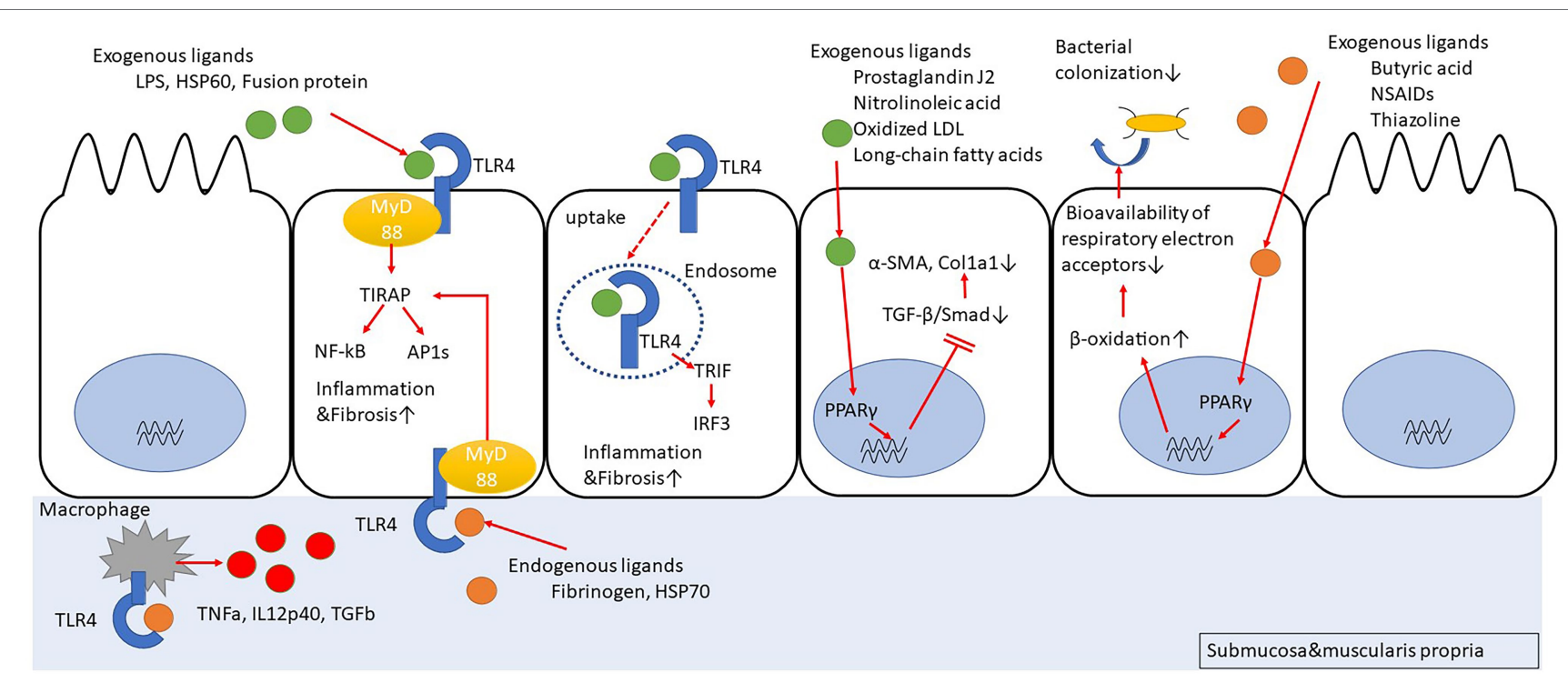

FIGURE 1 | Peroxisome proliferator-activating receptor gamma (PPAR $\gamma$ ) suppresses fibrosis by inhibiting Smad. PPAR $\gamma$ promotes cellular $\beta$-oxidation and inhibits bacterial colonization in intestinal epithelial cells. Toll-like receptor 4 (TLR4) stimulation induces inflammation/fibrosis. Macrophages activated with TLR4 stimulation produce pro-inflammatory cytokines.

et al., 2014). Although there have been no studies regarding the relationship between $\operatorname{PPAR} \gamma$ expression and microbiota composition in the intestines of IBD patients, disruption of gut microbiota can result in inappropriate PPAR $\gamma$ signaling responses in the intestinal epithelial cells, leading to further growth of the pathogenic gut bacteria and contributing to the exacerbation of UC. Furthermore, PPAR $\gamma$ is associated with response to chemical stimuli. For instance, when mice with a targeted disruption of the PPAR $\gamma$ gene in the intestinal epithelial cells (generated using the villin-Cre transgene and floxed PPAR $\gamma$ allele) were treated with dextran sodium sulfate (DSS), the expressions of interleukin 6 (IL-6), IL-1 $\beta$, and TGF $\alpha$ mRNAs were increased in their colons, as compared to the corresponding levels in the control mice (Adachi et al., 2006). Interestingly, in the DSS model mice, administration of pioglitazone or rosiglitazone, which are full agonists of PPAR $\gamma$, can improve intestinal inflammation (Adachi et al., 2006; da Rocha et al., 2020). The novel 5-ASA analog, GED-0507-34 Levo (GED), is also able to activate PPAR $\gamma$ and suppress the expression of the primary protein markers of fibrosis, namely alpha-smooth muscle actin ( $\alpha$-SMA) and collagen I-II, by inhibiting the TGF- $\beta /$ Smad pathway in the DSS mouse model as well as in human intestinal fibroblasts (Speca et al., 2016). Hence, PPAR $\gamma$ agonists can function as therapeutic targets that can cause suppression of inflammation and inhibition of inflammation-related fibrosis.

On the contrary, it is interesting to note that the PPAR $\gamma$ full agonists have the ability to induce differentiation of fibroblasts into adipocytes (Tontonoz et al., 1994a,b). Therefore, the use of PPAR $\gamma$ full agonists may induce submucosal fat deposition (SFD) due to adipocyte differentiation. The SFD is a condition in which a low-attenuation inner ring around the intestinal lumen is surrounded by a concentric, high-attenuation outer ring, known to radiologists as the "halo sign" on computed tomography (CT) imaging, and it has been implicated in the refractoriness of CD (Jones et al., 1986; Ahualli, 2007; Giaslakiotis et al., 2008). However, SFD is not necessarily specific for CD (Muldowney et al., 1995), and its correlation with creeping fat is unclear. Nevertheless, the adipocytes release pro-inflammatory and fibrotic cytokines; therefore, it would be desirable to use a partial agonist in PPAR $\gamma$-targeted therapy to avoid inducing adipocyte differentiation.

To date, PPAR $\gamma$-targeted therapy has been extensively researched for lifestyle-related diseases, such as diabetes and non-alcoholic fatty liver disease (NAFLD; Janani and Ranjitha Kumari, 2015; Cheng et al., 2019), but human applications have been partly undermined by metabolic dysregulation and carcinogenicity issues (Peters et al., 2012; Wright et al., 2014; Aghamohammadzadeh et al., 2015). Moreover, the mechanism of action of PPAR $\gamma$ agonists is complex; particularly, the mechanisms by which the ligands exhibit organ-specific sensitivity and strength as well as the differences in the temporal changes in response to ligands remain unclear. However, for the treatment of fibrosis in $\mathrm{CD}$, the side effects may be improved by using localized and short- or mediumterm drug administration instead of administering systemic and long-term drug therapy, as in the case of treating lifestylerelated diseases. In developing PPAR $\gamma$-based treatment, the large number of PPAR $\gamma$ agonists that have already been discovered by computer and high-throughput screening proves to be advantageous (Lewis et al., 2010; Otake et al., 2011; Liu et al., 2015). Additionally, the newly-developed highthroughput screening of intestinal organoid models and data mining of previously screened PPAR ligands might accelerate the research and development (Rossi et al., 2018; Du et al., 2020; Lukonin et al., 2021; Rayner et al., 2021). 


\section{TOLL-LIKE RECEPTOR 4}

The TLR4 belongs to a family of single transmembrane receptor proteins called the TLRs that activate innate immune responses by recognizing bacterial and viral components. In mammals, 11 types of TLRs have been identified (Akira and Takeda, 2004; Figure 1). Initially, TLR4 was identified as a receptor for lipopolysaccharide (LPS) of Gram-negative bacilli (Hoshino et al., 1999). However, further studies have revealed that it also functions as a receptor for other exogenous factors, such as heat-shock protein 60 (HSP60) from fungi (Bulut et al., 2002), respiratory syncytial virus (RSV)-derived fusion protein (Kurt-Jones et al., 2000), and taxol from plants (Kawasaki et al., 2000), as well as host-derived endogenous factors (Okamura et al., 2001; Johnson et al., 2002), including fibrinogen (Smiley et al., 2001) and HSP70 (Vabulas et al., 2002). After TLR4 recognizes its ligands, the major downstream signaling pathways that are stimulated include activation of NF- $\mathrm{KB}$ and activator protein 1 (AP1) via myeloid differentiation primary response 88 (MyD88)-dependent toll/interleukin-1 receptor domaincontaining adapter protein (TIRAP) or activation of interferon regulatory factor 3 (IRF3) via MyD88-independent toll/ interleukin-1 receptor (TIR)-domain-containing adapter-inducing interferon- $\beta$ (TRIF). The TLR4 signaling pathway can induce cytokine production, such as tumor necrosis factor-alpha (TNF- $\alpha$ ) and type I interferon (IFN), B cell proliferation, and maturation of dendritic cells to activate infection defense mechanisms (Verstrepen et al., 2008; Watts et al., 2010; Kawasaki and Kawai, 2014). In a comparison of TLR expression in primary intestinal epithelial cells between healthy controls and IBD patients, it was revealed that in the healthy controls, TLR3 and TLR5 were predominantly expressed, with little expression of TLR2 and TLR4, whereas in the CD patients, TLR3 expression was predominantly decreased and TLR4 expression was increased (Cario and Podolsky, 2000; Brown et al., 2014). In fact, the number of macrophages strongly expressing TLR4 was high in the inflamed mucosal lamina propria of the colon in CD patients (Hausmann et al., 2002). Based on this observation, many studies focused on determining the association between CD and TLR4 polymorphism. However, the abovementioned significant association was observed only in European Caucasians (Arnott et al., 2004; Franchimont et al., 2004; Brand et al., 2005; Fries et al., 2005), but not in non-Caucasian individuals or in non-European countries (Oostenbrug et al., 2005; Zouiten-Mekki et al., 2009). Therefore, it is likely that there are regional differences regarding this association. A meta-analysis integrating the above studies revealed an association between TLR4 Asp 299 Gly and IBD susceptibility in Caucasians but not in Asians (Cheng et al., 2015). Additionally, the data suggested that the association of IBD susceptibility with TLR4 Thr 399 lle might only occur in Caucasians.

The relationship between TLR4 and colonic fibrosis has been investigated using TLR4 knockout (KO) mice with the DSS colitis model (Jun et al., 2020). The results indicate that the TLR4 gene-deficient mice exhibit a reduced colonic inflammation as well as a decrease in the infiltration of macrophages into the colon, thereby resulting in reduced collagen deposition and intestinal fibrosis. Additionally, the production of TNF- $\alpha$, IL-12p 40 , and TGF- $\beta$ was reduced in the peritoneal macrophages of the mice lacking the TLR4 gene.

Certain studies have demonstrated that the direct stimulation of TLR4 with LPS in myofibroblasts derived from mouse intestine might activate the myofibroblasts via multiple pathways, such as phosphoinositide 3 (PI3) kinase, p38 mitogen-activated protein kinase (MAPK), and NF-KB, ultimately contributing to innate immune responses (Otte et al., 2003; Walton et al., 2009). Furthermore, the accumulation of submucosal fibroblasts and collagen is reduced when MyD88-deficient mice are subjected to enteritis (Månsson et al., 2012; Zhao et al., 2020). However, the expressions of TLR2, TLR4, and TLR5 are much weaker in colonic myofibroblasts than in the crypt epithelial cells of IBD patients (Brown et al., 2014).

\section{ADHERENT INVASIVE Escherichia coli}

Incidentally, $\mathrm{CD}$ patients have an abnormal intestinal microflora composition, and these microorganisms are closely related to the inflammation and intestinal stenosis observed in CD. Specifically, a decreased occurrence of phylum Firmicutes and an increased occurrence of phylum Proteobacteria, especially Enterobacteriaceae, have been observed in $C D$ patients with refractory inflammation or intestinal stricture (Frank et al., 2007; Sokol et al., 2020). Additionally, gene polymorphisms, as in the genes encoding autophagy-related 16 like 1 protein (ATG16L1) and nucleotide-binding oligomerization domain-containing protein 2 (NOD2; Hugot et al., 2001), are associated with the risk of developing CD (Hampe et al., 2007; Parkes et al., 2007). Adherent/invasive Escherichia coli (AIEC) in the intestine is most frequently isolated from the terminal part of the ileum of $\mathrm{CD}$ patients, thereby suggesting that AIEC may contribute to fibrosis (Darfeuille-Michaud et al., 2004; Small et al., 2013; Rieder et al., 2017). In fact, AIEC has been detected in $46.7 \%$ of CD patients compared to its occurrence in only $13.3 \%$ of healthy subjects (Sarabi Asiabar et al., 2018). AIEC requires a type IV secretion system (T4SS) to form biofilms in the intestinal tract and settle on the intestinal epithelial cells (Figure 2). Moreover, Escherichia coli isolates from CD patients are rich in T4SS, which is probably involved in the disease activity (Elhenawy et al., 2021). Interestingly, patients with serum antibodies to specific microbial peptides have an earlier onset of fibrostenosis and display early complications of $\mathrm{CD}$ (Dubinsky et al., 2008). Furthermore, creeping fat, specific for $\mathrm{CD}$, promotes interaction with gut bacteria that have migrated into the submucosa, thereby contributing to the activation of immune responses (Suau et al., 2021). These data suggest that AIEC may exacerbate the inflammation and stenosis associated with CD. Additionally, AIEC secretes Yersiniabactin (Perry and Fetherston, 2011), an iron-chelating agent, to incorporate iron into its cells; however, this Yersiniabactin may help some bacteria to infect the subepithelial 


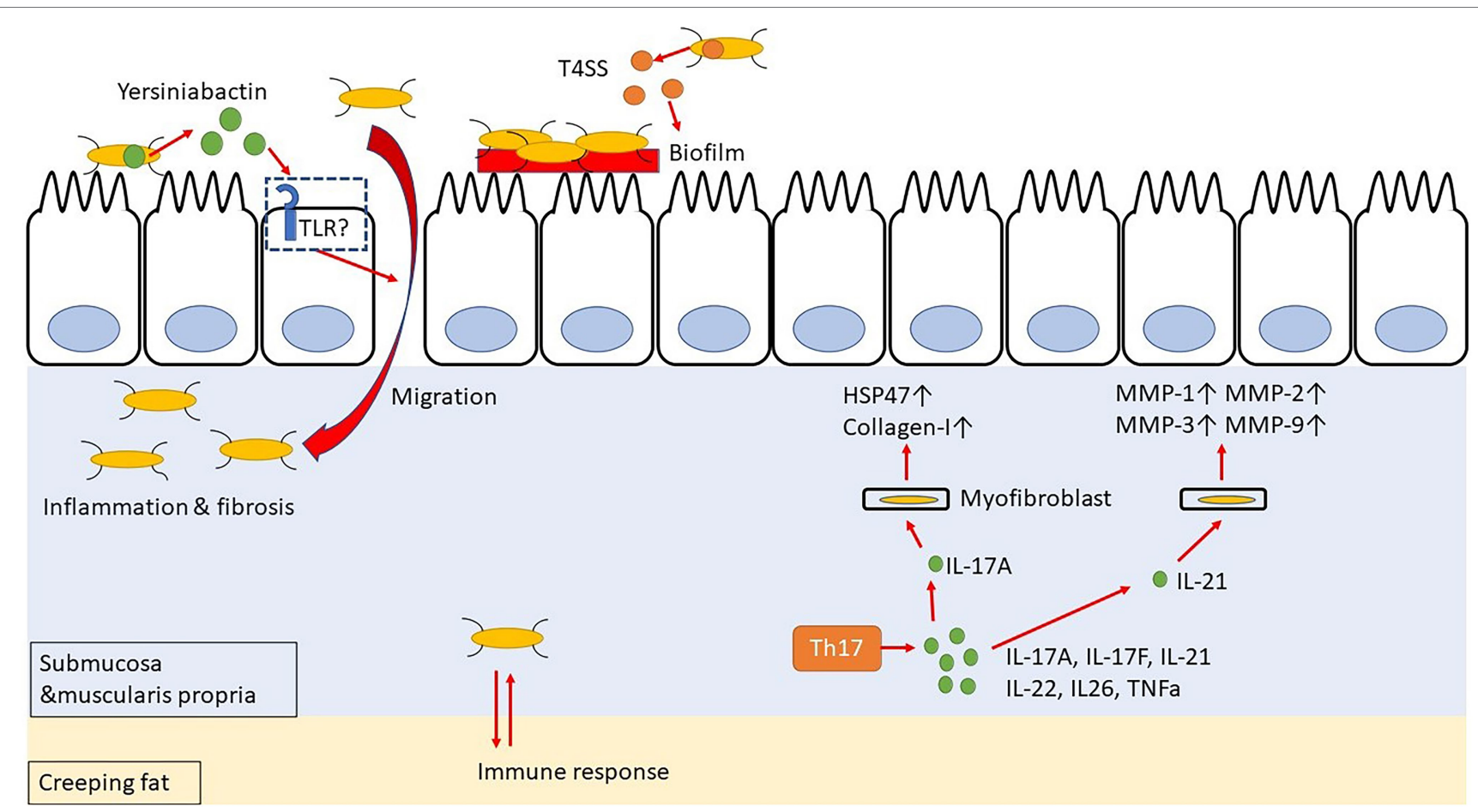

FIGURE 2 | Yersiniabactin secreted by adherent-invasive Escherichia coli (AIEC) helps bacteria to transfer to submucosa, and bacteria in submucosa have mutual immune response with Creeping fat. Th17 cell-related cytokines promote fibrosis by acting on myofibroblast.

layers of the intestine, thereby causing inflammation and intestinal fibrosis (Kim et al., 2005; Ellermann et al., 2019).

\section{Th17 CELL IMMUNE RESPONSE}

The Th17 cells are differentiated from naïve T cells upon TGF- $\beta$ and IL-6 stimulation (Sutton et al., 2006; Ruan et al., 2011), and they produce IL-17A, IL-17F, IL-21, IL-22, IL-26, and TNF- $\alpha$ (Cua and Tato, 2010; Hundorfean et al., 2012; Figure 2). The IL-17 stimulation activates the SEF/IL-17R (SEFIR) domain, which is closely related to the TIR domain of the IL-17R receptor. It thereby activates $\mathrm{NF}-\mathrm{\kappa B}$ and $\mathrm{AP}-1$ signaling through NF- $\kappa B$ activator 1 (ACT-1) and tumor necrosis factor receptor (TNFR)-associated factor 6 (TRAF-6), respectively (Moseley et al., 2003; Gaffen, 2009; Wang et al., 2013). The NF- $\kappa B$ and AP-1 signaling induce the secretion of IL-1, IL- 6 , TNF- $\alpha$, MMPs, and antimicrobial peptides. Hence, IL-17 has a pro-inflammatory role and can protect against extracellular parasitic as well as bacterial infections (Ye et al., 2001; Raffatellu et al., 2008; Lin et al., 2009). Incidentally, IL-17 and IL-21 are overexpressed in the colonic mucosa of UC patients, while IL-17, IL-21, and IL-22 are overexpressed in the colonic mucosa of CD patients (Fujino et al., 2003; Andoh et al., 2005; Monteleone et al., 2005; Brand et al., 2006). Therefore, the Th17-related cytokines are involved in the pathophysiology of both UC and CD. In CD, IL-17+ CD3+ T cells and CD68+ cells are scattered in the submucosa and muscularis propria, and some of these cells produce IFN- $\boldsymbol{\gamma}$ (Fujino et al., 2003; Annunziato et al.,
2007). Genome-wide association studies have revealed that IL23R and five genes involved in Th17 differentiation, namely the $I L 12 B$, Janus kinase 2 (JAK2), signal transducer and activator of transcription 3 (STAT3), C-C motif chemokine receptor 6 (CCR6), and TNFF15, are associated with the susceptibility to CD (Barrett et al., 2008).

In patients with CD, IL-17A is overexpressed in the stenotic intestine, as compared to its expression in the tissues of the non-stenotic area (Biancheri et al., 2013). Interestingly, both IL-17A and HSP47 expressions are enhanced in the colons of patients with active CD. Moreover, IL-17A promotes the expression of HSP47 and collagen I in intestinal myofibroblasts and CCD-18Co cells isolated from patients. In fact, knockdown of HSP47 in these cells inhibits IL-17A-induced collagen I production (Honzawa et al., 2014). Additionally, IL-17A treatment of IEC-6 cells (a rat small intestinal cell) induces EMT, decreases E-cadherin expression, and increases vimentin, snail, and $\alpha$-SMA expression (Zhang et al., 2018). It has also been reported that IL-21 boosts the Th1 response, which, in turn, stimulates the intestinal fibroblasts to secrete MMPs in response of CD (Monteleone et al., 2006). Incidentally, both Th1 and Th17 immune responses are involved in the trinitrobenzene sulfonic acid (TNBS)-induced colitis mice model (Zhu et al., 2012). In fact, administration of an anti-IL-17 antibody to mice with chronic colitis, which was induced by repeated intra-rectal administration of TNBS, decreases the expression of fibrosis-related cytokines, such as collagen 3, TNF- $\alpha$, TIMP metallopeptidase inhibitor 1 (TIMP-1), and MMP-2, as well as inflammatory cytokines, namely IL-1 $\beta$, 
TGF- $\beta 1$, and TNF- $\alpha$, ultimately resulting in a suppressed fibrosis (Zhang et al., 2018; Li et al., 2020). However, anti-IL-17A antibody (secukinumab) and anti-IL-17-receptor antibody (brodalumab) failed to demonstrate efficacy in the treatment of CD (Hueber et al., 2012; Mozaffari et al., 2015). Therefore, rather than direct inhibition of IL-17, IL-17 downstream pathways, such as HSP47, and other IL-17-based cytokines, such as IL-21, may be targets for avoiding intestinal fibrosis.

\section{PLASMINOGEN ACTIVATOR INHIBITOR-1}

Plasminogen activator inhibitor-1 (PAI-1) is a protein with a molecular weight of approximately $42,700 \mathrm{Da}$. It is mainly synthesized and secreted by vascular endothelial cells and hepatocytes. However, adipocytes and certain other cells also contribute to its production (Sillen and Declerck, 2021). Incidentally, PAI-1 is an inhibitor that regulates the fibrinolytic reaction by precisely forming a 1:1 irreversible bond with tissue plasminogen activator (tPA) and thereby inactivating it. Clinically, blood PAI-1 levels help to understand the pathogenesis of disseminated intravascular coagulation (DIC), a disease of the coagulation-fibrinolysis system (Gando et al., 2016; Hoshino et al., 2020; Morrow et al., 2021). Additionally, the expression of PAI-1 increases with age (Yamamoto et al., 2005). Elevated levels of TNF- $\alpha$, IL- 6 , and TGF- $\beta$ induce the expression of PAI-1 (Samad et al., 1999; Alessi et al., 2000; Rega et al., 2005). Subsequently, PAI-1 suppresses tPA production and prevents the conversion of plasminogen into plasmin, thereby resulting in a decrease in MMPs and the consequent inhibition of tissue fiber degradation (Munakata et al., 2015). Incidentally, PAI-1 is a major downstream target of TGF- $\beta$ signaling, and its transcription is directly regulated by Smad3 (Samarakoon and Higgins, 2008). In IBD patients as well as in mice colitis models, the expression of PAI-1 is extensive inactive lesions, and PAI- 1 and its direct target tPA play an essential role in the regulation of intestinal inflammation (Alkim et al., 2011; Kaiko et al., 2019; Su et al., 2020). Moreover, in the intestinal mucosa of the terminal ileum of patients with active CD, TGF- $\beta$ and PAI- 1

\section{REFERENCES}

Acedo, S. C., Gotardo, E. M. F., Lacerda, J. M., de Oliveira, C. C., de Oliveira Carvalho, P., and Gambero, A. (2011). Perinodal adipose tissue and mesenteric lymph node activation during reactivated TNBS-colitis in rats. Dig. Dis. Sci. 56, 2545-2552. doi: 10.1007/s10620-011-1644-8

Adachi, M., Kurotani, R., Morimura, K., Shah, Y., Sanford, M., Madison, B. B., et al. (2006). Peroxisome proliferator activated receptor gamma in colonic epithelial cells protects against experimental inflammatory bowel disease. Gut 55, 1104-1113. doi: 10.1136/gut.2005.081745

Aghamohammadzadeh, N., Niafar, M., Dalir Abdolahinia, E., Najafipour, F., Mohamadzadeh Gharebaghi, S., Adabi, K., et al. (2015). The effect of pioglitazone on weight, lipid profile and liver enzymes in type 2 diabetic patients. Ther. Adv. Endocrinol. Metab. 6, 56-60. doi: 10.1177/2042018815574229

Ahualli, J. (2007). The fat halo sign. Radiology 242, 945-946. doi: 10.1148/ radiol.2423041600

Akira, S., and Takeda, K. (2004). Toll-like receptor signalling. Nat. Rev. Immunol. 4, 499-511. doi: 10.1038/nri1391 levels are elevated with a positive correlation (Imai et al., 2020). Mice with TNBS-induced intestinal fibrosis also exhibit elevated PAI-1, and administration of TM5275, which blocks PAI-1/tPA complex formation, in these mice leads to an increase in MMP9 expression that can ameliorate fibrosis (Ibrahim et al., 2014; Yahata et al., 2017; Imai et al., 2020).

\section{CONCLUSION AND PROSPECTS}

In recent years, there has been an expansion in the knowledge regarding the associations between organ fibrosis and the underlying molecular pathways or functions. This may help to elucidate the molecular mechanism of intestinal fibrosis with respect to IBD. However, large-scale screening of the molecular structure, toxicity, and therapeutic efficacy of the potential therapeutic agents is essential. Hence, further development and improvement of high-throughput screening techniques, such as computer screening, organoid-based screening, and nematode-based screening (de Sousa Figueiredo et al., 2021) are desirable for the development of novel treatment strategies for CD.

\section{AUTHOR CONTRIBUTIONS}

$\mathrm{YH}$ drafted the manuscript. $\mathrm{YH}$ and $\mathrm{HN}$ critically revised the manuscript. All authors contributed to the article and approved the submitted version.

\section{FUNDING}

This work was supported in part by Health and Labor Sciences Research Grants for research on intractable diseases from the MHLW of Japan (Investigation and Research for intractable Inflammatory Bowel Disease to HN) and JSPS KAKENHI Grant Number JP $21 \mathrm{~K} 07919$ (to YH). The funders of the study had no role in the study design, data collection, data analysis, data interpretation, or writing of the report.

Alessi, M. C., Bastelica, D., Morange, P., Berthet, B., Leduc, I., Verdier, M., et al. (2000). Plasminogen activator inhibitor 1, transforming growth factor-betal, and BMI are closely associated in human adipose tissue during morbid obesity. Diabetes 49, 1374-1380. doi: 10.2337/diabetes.49.8.1374

Alkim, H., Ayaz, S., Alkim, C., Ulker, A., and Sahin, B. (2011). Continuous active state of coagulation system in patients with nonthrombotic inflammatory bowel disease. Clin. Appl. Thromb. Hemost. 17, 600-604. doi: 10.1177/1076029611405034

Andoh, A., Zhang, Z., Inatomi, O., Fujino, S., Deguchi, Y., Araki, Y., et al. (2005). Interleukin-22, a member of the IL-10 subfamily, induces inflammatory responses in colonic subepithelial myofibroblasts. Gastroenterology 129, 969-984. doi: 10.1053/j.gastro.2005.06.071

Annunziato, F., Cosmi, L., Santarlasci, V., Maggi, L., Liotta, F., Mazzinghi, B., et al. (2007). Phenotypic and functional features of human Th17 cells. J. Exp. Med. 204, 1849-1861. doi: 10.1084/jem.20070663

Arnott, I. D. R., Nimmo, E. R., Drummond, H. E., Fennell, J., Smith, B. R. K., MacKinlay, E., et al. (2004). NOD2/CARD15, TLR4 and CD14 mutations in Scottish and Irish Crohn's disease patients: evidence for genetic heterogeneity within Europe? Genes Immun. 5, 417-425. doi: 10.1038/sj.gene.6364111 
Barrett, J. C., Hansoul, S., Nicolae, D. L., Cho, J. H., Duerr, R. H., Rioux, J. D., et al. (2008). Genome-wide association defines more than 30 distinct susceptibility loci for Crohn's disease. Nat. Genet. 40, 955-962. doi: 10.1038/ ng. 175

Bettenworth, D., and Rieder, F. (2017). Pathogenesis of intestinal fibrosis in inflammatory bowel disease and perspectives for therapeutic implication. Dig. Dis. 35, 25-31. doi: 10.1159/000449079

Biancheri, P., Pender, S. L., Ammoscato, F., Giuffrida, P., Sampietro, G., Ardizzone, S., et al. (2013). The role of interleukin 17 in Crohn's diseaseassociated intestinal fibrosis. Fibrogenesis Tissue Repair 6:13. doi: 10.1186/1755-1536-6-13

Brand, S., Beigel, F., Olszak, T., Zitzmann, K., Eichhorst, S. T., Otte, J.-M., et al. (2006). IL-22 is increased in active Crohn's disease and promotes pro-inflammatory gene expression and intestinal epithelial cell migration. Am. J. Physiol. Gastrointest. Liver Physiol. 290, G827-G838. doi: 10.1152/ ajpgi.00513.2005

Brand, S., Staudinger, T., Schnitzler, F., Pfennig, S., Hofbauer, K., Dambacher, J., et al. (2005). The role of toll-like receptor 4 Asp299Gly and Thr399Ile polymorphisms and CARD15/NOD2 mutations in the susceptibility and phenotype of Crohn's disease. Inflamm. Bowel Dis. 11, 645-652. doi: 10.1097/01. mib.0000168372.94907.d2

Brown, M., Hughes, K. R., Moossavi, S., Robins, A., and Mahida, Y. R. (2014). Toll-like receptor expression in crypt epithelial cells, putative stem cells and intestinal myofibroblasts isolated from controls and patients with inflammatory bowel disease. Clin. Exp. Immunol. 178, 28-39. doi: 10.1111/cei.12381

Bulut, Y., Faure, E., Thomas, L., Karahashi, H., Michelsen, K. S., Equils, O., et al. (2002). Chlamydial heat shock protein 60 activates macrophages and endothelial cells through toll-like receptor 4 and MD2 in a MyD88dependent pathway. J. Immunol. 168, 1435-1440. doi: 10.4049/ jimmunol.168.3.1435

Byndloss, M. X., Olsan, E. E., Rivera-Chávez, F., Tiffany, C. R., Cevallos, S. A., Lokken, K. L., et al. (2017). Microbiota-activated PPAR- $\gamma$ signaling inhibits dysbiotic Enterobacteriaceae expansion. Science 357, 570-575. doi: 10.1126/ science.aam 9949

Cario, E., and Podolsky, D. K. (2000). Differential alteration in intestinal epithelial cell expression of toll-like receptor 3 (TLR3) and TLR4 in inflammatory bowel disease. Infect. Immun. 68, 7010-7017. doi: 10.1128/IAI.68.12.7010-7017.2000

Chan, L. S. A., and Wells, R. A. (2009). Cross-talk between PPARs and the partners of RXR: a molecular perspective. PPAR Res. 2009:925309. doi: $10.1155 / 2009 / 925309$

Cheng, H. S., Tan, W. R., Low, Z. S., Marvalim, C., Lee, J. Y. H., and Tan, N. S. (2019). Exploration and development of PPAR modulators in health and disease: an update of clinical evidence. Int. J. Mol. Sci. 20:5055. doi: 10.3390/ ijms20205055

Cheng, Y., Zhu, Y., Huang, X., Zhang, W., Han, Z., and Liu, S. (2015). Association between TLR2 and TLR4 gene polymorphisms and the susceptibility to inflammatory bowel disease: a meta-analysis. PLoS One 10:e0126803. doi: 10.1371/journal.pone.0126803

Crespi, M., Dulbecco, P., De Ceglie, A., and Conio, M. (2020). Strictures in Crohn's disease: from pathophysiology to treatment. Dig. Dis. Sci. 65, 1904-1916. doi: 10.1007/s10620-020-06227-0

Cua, D. J., and Tato, C. M. (2010). Innate IL-17-producing cells: the sentinels of the immune system. Nat. Rev. Immunol. 10, 479-489. doi: 10.1038/nri2800

Darfeuille-Michaud, A., Boudeau, J., Bulois, P., Neut, C., Glasser, A.-L., Barnich, N., et al. (2004). High prevalence of adherent-invasive Escherichia coli associated with ileal mucosa in Crohn's disease. Gastroenterology 127, 412-421. doi: 10.1053/j.gastro.2004.04.061

da Rocha, G. H. O., de Paula-Silva, M., Broering, M. F., Scharf, P. R. D. S., Matsuyama, L. S. A. S., Maria-Engler, S. S., et al. (2020). Pioglitazonemediated attenuation of experimental colitis relies on cleaving of annexin A1 released by macrophages. Front. Pharmacol. 11:591561. doi: 10.3389/ fphar.2020.591561

de Sousa Figueiredo, M. B., Pradel, E., George, F., Mahieux, S., Houcke, I., Pottier, M., et al. (2021). Adherent-invasive and non-invasive Escherichia coli isolates differ in their effects on Caenorhabditis elegans' lifespan. Microorganisms 9:1823. doi: 10.3390/microorganisms 9091823

Desreumaux, P., Ernst, O., Geboes, K., Gambiez, L., Berrebi, D., Müller-Alouf, H., et al. (1999). Inflammatory alterations in mesenteric adipose tissue in Crohn's disease. Gastroenterology 117, 73-81. doi: 10.1016/s0016-5085(99)70552-4
Du, Y., Li, X., Niu, Q., Mo, X., Qui, M., Ma, T., et al. (2020). Development of a miniaturized $3 \mathrm{D}$ organoid culture platform for ultra-high-throughput screening. J. Mol. Cell Biol. 12, 630-643. doi: 10.1093/jmcb/mjaa036

Dubinsky, M. C., Kugathasan, S., Mei, L., Picornell, Y., Nebel, J., Wrobel, I., et al. (2008). Increased immune reactivity predicts aggressive complicating Crohn's disease in children. Clin. Gastroenterol. Hepatol. 6, 1105-1111. doi: 10.1016/j.cgh.2008.04.032

Dubuquoy, L., Jansson, E. A., Deeb, S., Rakotobe, S., Karoui, M., Colombel, J.F., et al. (2003). Impaired expression of peroxisome proliferator-activated receptor gamma in ulcerative colitis. Gastroenterology 124, 1265-1276. doi: 10.1016/s0016-5085(03)00271-3

Elhenawy, W., Hordienko, S., Gould, S., Oberc, A. M., Tsai, C. N., Hubbard, T. P., et al. (2021). High-throughput fitness screening and transcriptomics identify a role for a type IV secretion system in the pathogenesis of Crohn's diseaseassociated Escherichia coli. Nat. Commun. 12:2032. doi: 10.1038/ s41467-021-22306-w

Ellermann, M., Gharaibeh, R. Z., Fulbright, L., Dogan, B., Moore, L. N., Broberg, C. A., et al. (2019). Yersiniabactin-producing adherent/invasive Escherichia coli promotes inflammation-associated fibrosis in Gnotobiotic Il10-/- mice. Infect. Immun. 87, e00587-e00519. doi: 10.1128/IAI.00587-19

Fiocchi, C., and Lund, P. K. (2011). Themes in fibrosis and gastrointestinal inflammation. Am. J. Physiol. Gastrointest. Liver Physiol. 300, G677-G683. doi: 10.1152/ajpgi.00104.2011

Franchimont, D., Vermeire, S., El Housni, H., Pierik, M., Van Steen, K., Gustot, T., et al. (2004). Deficient host-bacteria interactions in inflammatory bowel disease? The toll-like receptor (TLR)-4 Asp299gly polymorphism is associated with Crohn's disease and ulcerative colitis. Gut 53, 987-992. doi: 10.1136/ gut.2003.030205

Frank, D. N., St Amand, A. L., Feldman, R. A., Boedeker, E. C., Harpaz, N., and Pace, N. R. (2007). Molecular-phylogenetic characterization of microbial community imbalances in human inflammatory bowel diseases. Proc. Natl. Acad. Sci. U. S. A. 104, 13780-13785. doi: 10.1073/pnas.0706625104

Fries, W., Renda, M. C., Lo Presti, M. A., Raso, A., Orlando, A., Oliva, L., et al. (2005). Intestinal permeability and genetic determinants in patients, first-degree relatives, and controls in a high-incidence area of Crohn's disease in southern Italy. Am. J. Gastroenterol. 100, 2730-2736. doi: 10.1111/j.1572-0241.2005.00325.x

Fujino, S., Andoh, A., Bamba, S., Ogawa, A., Hata, K., Araki, Y., et al. (2003). Increased expression of interleukin 17 in inflammatory bowel disease. Gut 52, 65-70. doi: 10.1136/gut.52.1.65

Gaffen, S. L. (2009). Structure and signalling in the IL-17 receptor family. Nat. Rev. Immunol. 9, 556-567. doi: 10.1038/nri2586

Gando, S., Levi, M., and Toh, C.-H. (2016). Disseminated intravascular coagulation. Nat. Rev. Dis. Primers 2:16037. doi: 10.1038/nrdp.2016.37

Giaslakiotis, K., Baird, A., and Warren, B. F. (2008). Submucosal fat deposition in a patient with Crohn's disease: the fat halo sign. Histopathology 53, 611-612. doi: 10.1111/j.1365-2559.2008.03130.x

Hampe, J., Franke, A., Rosenstiel, P., Till, A., Teuber, M., Huse, K., et al. (2007). A genome-wide association scan of nonsynonymous SNPs identifies a susceptibility variant for Crohn disease in ATG16L1. Nat. Genet. 39, 207-211. doi: 10.1038/ng1954

Hausmann, M., Kiessling, S., Mestermann, S., Webb, G., Spöttl, T., Andus, T., et al. (2002). Toll-like receptors 2 and 4 are up-regulated during intestinal inflammation. Gastroenterology 122, 1987-2000. doi: 10.1053/ gast.2002.33662

Honzawa, Y., Nakase, H., Shiokawa, M., Yoshino, T., Imaeda, H., Matsuura, M., et al. (2014). Involvement of interleukin-17A-induced expression of heat shock protein 47 in intestinal fibrosis in Crohn's disease. Gut 63, 1902-1912. doi: 10.1136/gutjnl-2013-305632

Hoshino, K., Nakashio, M., Maruyama, J., Irie, Y., Kawano, Y., and Ishikura, H. (2020). Validating plasminogen activator inhibitor-1 as a poor prognostic factor in sepsis. Acute Med. Surg. 7:e581. doi: 10.1002/ams2.581

Hoshino, K., Takeuchi, O., Kawai, T., Sanjo, H., Ogawa, T., Takeda, Y., et al. (1999). Cutting edge: toll-like receptor 4 (TLR4)-deficient mice are hyporesponsive to lipopolysaccharide: evidence for TLR4 as the Lps gene product. J. Immunol. 162, 3749-3752.

Hueber, W., Sands, B. E., Lewitzky, S., Vandemeulebroecke, M., Reinisch, W., Higgins, P. D. R., et al. (2012). Secukinumab, a human anti-IL-17A monoclonal antibody, for moderate to severe Crohn's disease: unexpected results of a 
randomised, double-blind placebo-controlled trial. Gut 61, 1693-1700. doi: 10.1136/gutjnl-2011-301668

Hugot, J. P., Chamaillard, M., Zouali, H., Lesage, S., Cézard, J. P., Belaiche, J., et al. (2001). Association of NOD2 leucine-rich repeat variants with susceptibility to Crohn's disease. Nature 411, 599-603. doi: 10.1038/35079107

Hundorfean, G., Neurath, M. F., and Mudter, J. (2012). Functional relevance of T helper 17 (Th17) cells and the IL-17 cytokine family in inflammatory bowel disease. Inflamm. Bowel Dis. 18, 180-186. doi: 10.1002/ibd.21677

Iacucci, M., de Silva, S., and Ghosh, S. (2010). Mesalazine in inflammatory bowel disease: a trendy topic once again? Can. J. Gastroenterol. 24, 127-133. doi: $10.1155 / 2010 / 586092$

Ibrahim, A. A., Yahata, T., Onizuka, M., Dan, T., Van Ypersele De Strihou, C., Miyata, T., et al. (2014). Inhibition of plasminogen activator inhibitor type-1 activity enhances rapid and sustainable hematopoietic regeneration. Stem Cells 32, 946-958. doi: 10.1002/stem.1577

Imai, J., Yahata, T., Ichikawa, H., Ibrahim, A. A., Yazawa, M., Sumiyoshi, H., et al. (2020). Inhibition of plasminogen activator inhibitor-1 attenuates against intestinal fibrosis in mice. Intest Res. 18, 219-228. doi: 10.5217/ir.2019.00037

Janani, C., and Ranjitha Kumari, B. D. (2015). PPAR gamma gene-a review. Diabetes Metab. Syndr. 9, 46-50. doi: 10.1016/j.dsx.2014.09.015

Johnson, G. B., Brunn, G. J., Kodaira, Y., and Platt, J. L. (2002). Receptormediated monitoring of tissue well-being via detection of soluble heparan sulfate by toll-like receptor 4. J. Immunol. 168, 5233-5239. doi: 10.4049/ jimmunol.168.10.5233

Jones, B., Fishman, E. K., Hamilton, S. R., Rubesin, S. E., Bayless, T. M., Cameron, J. C., et al. (1986). Submucosal accumulation of fat in inflammatory bowel disease: CT/pathologic correlation. J. Comput. Assist. Tomogr. 10, 759-763. doi: 10.1097/00004728-198609000-00009

Jun, Y. K., Kwon, S. H., Yoon, H. T., Park, H., Soh, H., Lee, H. J., et al. (2020). Toll-like receptor 4 regulates intestinal fibrosis via cytokine expression and epithelial-mesenchymal transition. Sci. Rep. 10:19867. doi: 10.1038/ s41598-020-76880-y

Kaiko, G. E., Chen, F., Lai, C.-W., Chiang, I.-L., Perrigoue, J., Stojmirović, A., et al. (2019). PAI-1 augments mucosal damage in colitis. Sci. Transl. Med. 11:eaat0852. doi: $10.1126 /$ scitranslmed.aat 0852

Karmiris, K., Koutroubakis, I. E., Xidakis, C., Polychronaki, M., Voudouri, T., and Kouroumalis, E. A. (2006). Circulating levels of leptin, adiponectin, resistin, and ghrelin in inflammatory bowel disease. Inflamm. Bowel Dis. 12, 100-105. doi: 10.1097/01.MIB.0000200345.38837.46

Kawasaki, K., Akashi, S., Shimazu, R., Yoshida, T., Miyake, K., and Nishijima, M. (2000). Mouse toll-like receptor 4.MD-2 complex mediates lipopolysaccharidemimetic signal transduction by taxol. J. Biol. Chem. 275, 2251-2254. doi: $10.1074 /$ jbc.275.4.2251

Kawasaki, T., and Kawai, T. (2014). Toll-Like receptor Signaling pathways. Front. Immunol. 5:461. doi: 10.3389/fimmu.2014.00461

Kim, S. C., Tonkonogy, S. L., Albright, C. A., Tsang, J., Balish, E. J., Braun, J., et al. (2005). Variable phenotypes of enterocolitis in interleukin 10-deficient mice monoassociated with two different commensal bacteria. Gastroenterology 128, 891-906. doi: 10.1053/j.gastro.2005.02.009

Kroker, A. J., and Bruning, J. B. (2015). Review of the structural and dynamic mechanisms of PPAR $\gamma$ partial agonism. PPAR Res. 2015:e816856. doi: $10.1155 / 2015 / 816856$

Kurt-Jones, E. A., Popova, L., Kwinn, L., Haynes, L. M., Jones, L. P., Tripp, R. A., et al. (2000). Pattern recognition receptors TLR4 and CD14 mediate response to respiratory syncytial virus. Nat. Immunol. 1, 398-401. doi: $10.1038 / 80833$

Lawrance, I. C., Maxwell, L., and Doe, W. (2001a). Altered response of intestinal mucosal fibroblasts to profibrogenic cytokines in inflammatory bowel disease. Inflamm. Bowel Dis. 7, 226-236. doi: 10.1097/00054725-200108000-00008

Lawrance, I. C., Maxwell, L., and Doe, W. (2001b). Inflammation location, but not type, determines the increase in TGF-betal and IGF-1 expression and collagen deposition in IBD intestine. Inflamm. Bowel Dis. 7, 16-26. doi: 10.1097/00054725-200102000-00003

Lewis, S. N., Bassaganya-Riera, J., and Bevan, D. R. (2010). Virtual screening as a technique for PPAR modulator discovery. PPAR Res. 2010:861238. doi: $10.1155 / 2010 / 861238$

Li, J., Liu, L., Zhao, Q., and Chen, M. (2020). Role of Interleukin-17 in pathogenesis of intestinal fibrosis in mice. Dig. Dis. Sci. 65, 1971-1979. doi: $10.1007 /$ s10620-019-05969-w
Lin, Y., Ritchea, S., Logar, A., Slight, S., Messmer, M., Rangel-Moreno, J., et al. (2009). Interleukin-17 is required for T helper 1 cell immunity and host resistance to the intracellular pathogen Francisella tularensis. Immunity 31, 799-810. doi: 10.1016/j.immuni.2009.08.025

Liu, C., Feng, T., Zhu, N., Liu, P., Han, X., Chen, M., et al. (2015). Identification of a novel selective agonist of PPAR $\gamma$ with no promotion of adipogenesis and less inhibition of osteoblastogenesis. Sci. Rep. 5:9530. doi: 10.1038/ srep09530

Lukonin, I., Zinner, M., and Liberali, P. (2021). Organoids in image-based phenotypic chemical screens. Exp. Mol. Med. 53, 1495-1502. doi: 10.1038/ s12276-021-00641-8

Mangelsdorf, D. J., Thummel, C., Beato, M., Herrlich, P., Schütz, G., Umesono, K., et al. (1995). The nuclear receptor superfamily: the second decade. Cell 83, 835-839. doi: 10.1016/0092-8674(95)90199-x

Månsson, L. E., Montero, M., Zarepour, M., Bergstrom, K. S., Ma, C., Huang, T., et al. (2012). MyD88 signaling promotes both mucosal homeostatic and fibrotic responses during salmonella-induced colitis. Am. J. Physiol. Gastrointest. 303, G311-G323. doi: 10.1152/ajpgi.00038.2012

Mirza, A. Z., Althagafi, I. I., and Shamshad, H. (2019). Role of PPAR receptor in different diseases and their ligands: physiological importance and clinical implications. Eur. J. Med. Chem. 166, 502-513. doi: 10.1016/j.ejmech.2019.01.067

Monteleone, G., Caruso, R., Fina, D., Peluso, I., Gioia, V., Stolfi, C., et al. (2006). Control of matrix metalloproteinase production in human intestinal fibroblasts by interleukin 21. Gut 55, 1774-1780. doi: 10.1136/ gut.2006.093187

Monteleone, G., Monteleone, I., Fina, D., Vavassori, P., Del Vecchio Blanco, G., Caruso, R., et al. (2005). Interleukin-21 enhances T-helper cell type I signaling and interferon-gamma production in Crohn's disease. Gastroenterology 128, 687-694. doi: 10.1053/j.gastro.2004.12.042

Morrow, G. B., Whyte, C. S., and Mutch, N. J. (2021). A serpin With a finger in many PAIs: PAI-1's central function in Thromboinflammation and cardiovascular disease. Front. Cardiovasc. Med. 8:653655. doi: 10.3389/ fcvm.2021.653655

Moseley, T. A., Haudenschild, D. R., Rose, L., and Reddi, A. H. (2003). Interleukin-17 family and IL-17 receptors. Cytokine Growth Factor Rev. 14, 155-174. doi: 10.1016/S1359-6101(03)00002-9

Mozaffari, S., Nikfar, S., and Abdollahi, M. (2015). Inflammatory bowel disease therapies discontinued between 2009 and 2014. Expert Opin. Investig. Drugs 24, 949-956. doi: 10.1517/13543784.2015.1035432

Muldowney, S. M., Balfe, D. M., Hammerman, A., and Wick, M. R. (1995). "Acute" fat deposition in bowel wall submucosa: CT appearance. J. Comput. Assist. Tomogr. 19, 390-393. doi: 10.1097/00004728-199505000-00010

Munakata, S., Tashiro, Y., Nishida, C., Sato, A., Komiyama, H., Shimazu, H., et al. (2015). Inhibition of plasmin protects against colitis in mice by suppressing matrix metalloproteinase 9-mediated cytokine release from myeloid cells. Gastroenterology 148, 565.e4-578.e4. doi: 10.1053/j. gastro.2014.12.001

Okamura, Y., Watari, M., Jerud, E. S., Young, D. W., Ishizaka, S. T., Rose, J., et al. (2001). The extra domain A of fibronectin activates toll-like receptor 4. J. Biol. Chem. 276, 10229-10233. doi: 10.1074/jbc.M100099200

Oostenbrug, L. E., Drenth, J. P. H., de Jong, D. J., Nolte, I. M., Oosterom, E., van Dullemen, H. M., et al. (2005). Association between toll-like receptor 4 and inflammatory bowel disease. Inflamm. Bowel Dis. 11, 567-575. doi: 10.1097/01.mib.0000161305.81198.0f

Otake, K., Azukizawa, S., Fukui, M., Shibabayashi, M., Kamemoto, H., Miike, T., et al. (2011). A novel series of (S)-2,7-Substituted-1,2,3,4tetrahydroisoquinoline-3-carboxylic acids: peroxisome proliferator-activated receptor $\alpha / \gamma$ dual agonists with protein-tyrosine phosphatase 1B inhibitory activity. Chem. Pharm. Bull. 59, 1233-1242. doi: 10.1248/cpb.59.1233

Otte, J.-M., Rosenberg, I. M., and Podolsky, D. K. (2003). Intestinal myofibroblasts in innate immune responses of the intestine. Gastroenterology 124, 1866-1878. doi: 10.1016/S0016-5085(03)00403-7

Parkes, M., Barrett, J. C., Prescott, N. J., Tremelling, M., Anderson, C. A., Fisher, S. A., et al. (2007). Sequence variants in the autophagy gene IRGM and multiple other replicating loci contribute to Crohn's disease susceptibility. Nat. Genet. 39, 830-832. doi: 10.1038/ng2061

Perry, R. D., and Fetherston, J. D. (2011). Yersiniabactin iron uptake: mechanisms and role in Yersinia pestis pathogenesis. Microbes Infect. 13, 808-817. doi: 10.1016/j.micinf.2011.04.008 
Peters, J. M., Shah, Y. M., and Gonzalez, F. J. (2012). The role of peroxisome proliferator-activated receptors in carcinogenesis and chemoprevention. Nat. Rev. Cancer 12, 181-195. doi: 10.1038/nrc3214

Raffatellu, M., Santos, R. L., Verhoeven, D. E., George, M. D., Wilson, R. P., Winter, S. E., et al. (2008). Simian immunodeficiency virus-induced mucosal interleukin-17 deficiency promotes salmonella dissemination from the gut. Nat. Med. 14, 421-428. doi: 10.1038/nm1743

Rayner, M. L. D., Healy, J., and Phillips, J. B. (2021). Repurposing small molecules to target PPAR- $\gamma$ as new therapies for peripheral nerve injuries. Biomol. Ther. 11:1301. doi: 10.3390/biom11091301

Rega, G., Kaun, C., Weiss, T. W., Demyanets, S., Zorn, G., Kastl, S. P., et al. (2005). Inflammatory cytokines interleukin-6 and oncostatin $\mathrm{m}$ induce plasminogen activator inhibitor-1 in human adipose tissue. Circulation 111, 1938-1945. doi: 10.1161/01.CIR.0000161823.55935.BE

Rieder, F., Brenmoehl, J., Leeb, S., Schölmerich, J., and Rogler, G. (2007). Wound healing and fibrosis in intestinal disease. Gut 56, 130-139. doi: 10.1136/gut.2006.090456

Rieder, F., Fiocchi, C., and Rogler, G. (2017). Mechanisms, management, and treatment of fibrosis in patients with inflammatory bowel diseases. Gastroenterology 152, 340.e6-350.e6. doi: 10.1053/j.gastro.2016.09.047

Rieder, F., Zimmermann, E. M., Remzi, F. H., and Sandborn, W. J. (2013). Crohn's disease complicated by strictures: a systematic review. Gut 62, 1072-1084. doi: 10.1136/gutjnl-2012-304353

Rossi, G., Manfrin, A., and Lutolf, M. P. (2018). Progress and potential in organoid research. Nat. Rev. Genet. 19, 671-687. doi: 10.1038/s41576-018-0051-9

Rousseaux, C., Lefebvre, B., Dubuquoy, L., Lefebvre, P., Romano, O., Auwerx, J., et al. (2005). Intestinal antiinflammatory effect of 5-aminosalicylic acid is dependent on peroxisome proliferator-activated receptor-gamma. J. Exp. Med. 201, 1205-1215. doi: 10.1084/jem.20041948

Ruan, Q., Kameswaran, V., Zhang, Y., Zheng, S., Sun, J., Wang, J., et al. (2011). The Th17 immune response is controlled by the Rel-ROR $\gamma-\operatorname{ROR} \gamma \mathrm{T}$ transcriptional axis. J. Exp. Med. 208, 2321-2333. doi: 10.1084/jem.20110462

Samad, F., Uysal, K. T., Wiesbrock, S. M., Pandey, M., Hotamisligil, G. S., and Loskutoff, D. J. (1999). Tumor necrosis factor alpha is a key component in the obesity-linked elevation of plasminogen activator inhibitor 1. Proc. Natl. Acad. Sci. U. S. A. 96, 6902-6907. doi: 10.1073/pnas.96.12.6902

Samarakoon, R., and Higgins, P. J. (2008). Integration of non-SMAD and SMAD signaling in TGF- $\beta 1$-induced plasminogen activator inhibitor type-1 gene expression in vascular smooth muscle cells. Thromb. Haemost. 100, 976-983. doi: 10.1160/TH08-05-0273

Sarabi Asiabar, A., Asadzadeh Aghdaei, H., Sabokbar, A., Zali, M. R., and Feizabadi, M. M. (2018). Investigation of adherent-invasive E. coli in patients with Crohn's disease. Med. J. Islam Repub. Iran 32:11. doi: 10.14196/mjiri.32.11

Scarpa, M., Angriman, I., Barollo, M., Polese, L., Ruffolo, C., Bertin, M., et al. (2003). Risk factors for recurrence of stenosis in Crohn's disease. Acta Biomed. $74,80-83$.

Schäffler, A., and Herfarth, H. (2005). Creeping fat in Crohn's disease: travelling in a creeper lane of research? Gut 54, 742-744. doi: 10.1136/ gut.2004.061531

Sheehan, A. L., Warren, B. F., Gear, M. W., and Shepherd, N. A. (1992). Fatwrapping in Crohn's disease: pathological basis and relevance to surgical practice. Br. J. Surg. 79, 955-958. doi: 10.1002/bjs.1800790934

Sillen, M., and Declerck, P. J. (2021). A narrative review on plasminogen activator Inhibitor-1 and its (Patho)physiological role: to target or not to target? Int. J. Mol. Sci. 22:2721. doi: 10.3390/ijms22052721

Small, C.-L. N., Reid-Yu, S. A., McPhee, J. B., and Coombes, B. K. (2013). Persistent infection with Crohn's disease-associated adherent-invasive Escherichia coli leads to chronic inflammation and intestinal fibrosis. Nat. Commun. 4:1957. doi: 10.1038/ncomms2957

Smiley, S. T., King, J. A., and Hancock, W. W. (2001). Fibrinogen stimulates macrophage chemokine secretion through toll-like receptor 4. J. Immunol. 167, 2887-2894. doi: 10.4049/jimmunol.167.5.2887

Sokol, H., Brot, L., Stefanescu, C., Auzolle, C., Barnich, N., Buisson, A., et al. (2020). Prominence of ileal mucosa-associated microbiota to predict postoperative endoscopic recurrence in Crohn's disease. Gut 69, 462-472. doi: $10.1136 /$ gutjnl-2019-318719

Speca, S., Giusti, I., Rieder, F., and Latella, G. (2012). Cellular and molecular mechanisms of intestinal fibrosis. World J. Gastroenterol. 18, 3635-3661. doi: 10.3748 /wjg.v18.i28.3635
Speca, S., Rousseaux, C., Dubuquoy, C., Rieder, F., Vetuschi, A., Sferra, R., et al. (2016). Novel PPAR $\gamma$ modulator GED-0507-34 Levo ameliorates inflammation-driven intestinal fibrosis. Inflamm. Bowel Dis. 22, 279-292. doi: $10.1097 /$ MIB.0000000000000618

Su, R. C., Warner, E. A., Breidenbach, J. D., Lad, A., Blomquist, T. M., Kleinhenz, A. L., et al. (2020). CD40 receptor knockout protects against microcystin-LR (MCLR) prolongation and exacerbation of dextran sulfate sodium (DSS)-induced colitis. Biomedicine 8:E149. doi: 10.3390/biomedicines8060149

Suau, R., Pardina, E., Domènech, E., Lorén, V., and Manyé, J. (2021). The complex relationship between microbiota, immune response and creeping fat in Crohn's disease. J. Crohns Colitis jjab159. doi: 10.1093/ecco-jcc/jjab159 [Epub ahead of print]

Sutton, C., Brereton, C., Keogh, B., Mills, K. H. G., and Lavelle, E. C. (2006). A crucial role for interleukin (IL)-1 in the induction of IL-17-producing $\mathrm{T}$ cells that mediate autoimmune encephalomyelitis. J. Exp. Med. 203, 1685-1691. doi: 10.1084/jem.20060285

Tontonoz, P., Hu, E., Graves, R. A., Budavari, A. I., and Spiegelman, B. M. (1994a). mPPAR gamma 2: tissue-specific regulator of an adipocyte enhancer. Genes Dev. 8, 1224-1234. doi: 10.1101/gad.8.10.1224

Tontonoz, P., Hu, E., and Spiegelman, B. M. (1994b). Stimulation of adipogenesis in fibroblasts by PPAR gamma 2, a lipid-activated transcription factor. Cell 79, 1147-1156. doi: 10.1016/0092-8674(94)90006-x

Vabulas, R. M., Ahmad-Nejad, P., Ghose, S., Kirschning, C. J., Issels, R. D., and Wagner, H. (2002). HSP70 as endogenous stimulus of the toll/interleukin-1 receptor signal pathway. J. Biol. Chem. 277, 15107-15112. doi: 10.1074/jbc. M111204200

Van Assche, G., Geboes, K., and Rutgeerts, P. (2004). Medical therapy for Crohn's disease strictures. Inflamm. Bowel Dis. 10, 55-60. doi: 10.1097/00054725-200401000-00009

Verstrepen, L., Bekaert, T., Chau, T.-L., Tavernier, J., Chariot, A., and Beyaert, R. (2008). TLR-4, IL-1R and TNF-R signaling to NF- $\mathrm{kB}$ : variations on a common theme. Cell. Mol. Life Sci. 65, 2964-2978. doi: 10.1007/ s00018-008-8064-8

Walton, K. L. W., Holt, L., and Sartor, R. B. (2009). Lipopolysaccharide activates innate immune responses in murine intestinal myofibroblasts through multiple signaling pathways. Am. J. Physiol. Gastrointest. Liver Physiol. 296, G601-G611. doi: 10.1152/ajpgi.00022.2008

Wang, C., Wu, L., Bulek, K., Martin, B. N., Zepp, J. A., Kang, Z., et al. (2013). The psoriasis-associated D10N variant of the adaptor Actl with impaired regulation by the molecular chaperone hsp90. Nat. Immunol. 14, 72-81. doi: $10.1038 /$ ni.2479

Watts, C., West, M. A., and Zaru, R. (2010). TLR signalling regulated antigen presentation in dendritic cells. Curr. Opin. Immunol. 22, 124-130. doi: 10.1016/j.coi.2009.12.005

Weisberg, S. P., McCann, D., Desai, M., Rosenbaum, M., Leibel, R. L., and Ferrante, A. W. (2003). Obesity is associated with macrophage accumulation in adipose tissue. J. Clin. Invest. 112, 1796-1808. doi: 10.1172/ JCI19246

Wright, M. B., Bortolini, M., Tadayyon, M., and Bopst, M. (2014). Minireview: challenges and opportunities in development of PPAR agonists. Mol. Endocrinol. 28, 1756-1768. doi: 10.1210/me.2013-1427

Wynn, T. A. (2007). Common and unique mechanisms regulate fibrosis in various fibroproliferative diseases. J. Clin. Invest. 117, 524-529. doi: 10.1172/ JCI31487

Yahata, T., Ibrahim, A. A., Muguruma, Y., Eren, M., Shaffer, A. M., Watanabe, N., et al. (2017). TGF- $\beta$-induced intracellular PAI-1 is responsible for retaining hematopoietic stem cells in the niche. Blood 130, 2283-2294. doi: 10.1182/ blood-2017-02-767384

Yamamoto, K., Takeshita, K., Kojima, T., Takamatsu, J., and Saito, H. (2005). Aging and plasminogen activator inhibitor-1 (PAI-1) regulation: implication in the pathogenesis of thrombotic disorders in the elderly. Cardiovasc. Res. 66, 276-285. doi: 10.1016/j.cardiores.2004.11.013

Yamamoto-Furusho, J. K., Jacintez-Cazares, M., Furuzawa-Carballeda, J., and Fonseca-Camarillo, G. (2014). Peroxisome proliferator-activated receptors family is involved in the response to treatment and mild clinical course in patients with ulcerative colitis. Dis. Markers 2014:e932530. doi: $10.1155 / 2014 / 932530$

Ye, P., Rodriguez, F. H., Kanaly, S., Stocking, K. L., Schurr, J., Schwarzenberger, P., et al. (2001). Requirement of interleukin 17 receptor signaling for lung 
CXC chemokine and granulocyte colony-stimulating factor expression, neutrophil recruitment, and host defense. J. Exp. Med. 194, 519-528. doi: 10.1084/jem.194.4.519

Zhang, F., Lavan, B. E., and Gregoire, F. M. (2007). Selective modulators of PPAR- $\gamma$ activity: molecular aspects related to obesity and side-effects. PPAR Res. 2007:32696. doi: 10.1155/2007/32696

Zhang, H.-J., Zhang, Y.-N., Zhou, H., Guan, L., Li, Y., and Sun, M.-J. (2018). IL-17A promotes initiation and development of intestinal fibrosis through EMT. Dig. Dis. Sci. 63, 2898-2909. doi: 10.1007/s10620-018-5234-x

Zhao, S., Dejanovic, D., Yao, P., Bhilocha, S., Sadler, T., Schirbel, A., et al. (2020). Selective deletion of MyD88 signaling in $\alpha$-SMA positive cells ameliorates experimental intestinal fibrosis via post-transcriptional regulation. Mucosal Immunol. 13, 665-678. doi: 10.1038/s41385-020-0259-9

Zhu, M. Y., Lu, Y. M., Ou, Y. X., Zhang, H. Z., and Chen, W. X. (2012). Dynamic progress of 2,4,6-trinitrobenzene sulfonic acid induced chronic colitis and fibrosis in rat model. J. Dig. Dis. 13, 421-429. doi: 10.1111/j.1751-2980.2012.00607.x

Zouiten-Mekki, L., Kharrat, M., Karoui, S., Serghimi, M., Fekih, M., Matri, S., et al. (2009). Tolllike receptor 4 (TLR4) polymorphisms in Tunisian patients with Crohn's disease: genotype-phenotype correlation. BMC Gastroenterol. 9:62. doi: 10.1186/1471-230X-9-62

Conflict of Interest: The authors declare that the research was conducted in the absence of any commercial or financial relationships that could be construed as a potential conflict of interest.

Publisher's Note: All claims expressed in this article are solely those of the authors and do not necessarily represent those of their affiliated organizations, or those of the publisher, the editors and the reviewers. Any product that may be evaluated in this article, or claim that may be made by its manufacturer, is not guaranteed or endorsed by the publisher.

Copyright $\odot 2022$ Hayashi and Nakase. This is an open-access article distributed under the terms of the Creative Commons Attribution License (CC BY). The use, distribution or reproduction in other forums is permitted, provided the original author(s) and the copyright owner(s) are credited and that the original publication in this journal is cited, in accordance with accepted academic practice. No use, distribution or reproduction is permitted which does not comply with these terms. 